\title{
COMMENTARY
}

\section{Ticking the box of 'cultural safety' is not enough: why trauma-informed practice is critical to Indigenous healing}

\section{AUTHORS}

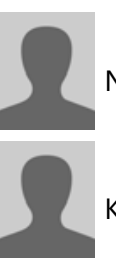

Nicole A Tujague ${ }^{1}$, Indigenous Research Academic *

\section{CORRESPONDENCE}

*Ms Nicole A Tujague nicole.tujague@me.com

\section{AFFILIATIONS}

${ }^{1}$ Gnibi College of Indigenous Peoples, Southern Cross University, Bilinga, Qld 4225, Australia; and The Seedling Group, Locked Bag 8200, GCMC, Queensland, Australia

2 The Seedling Group, Locked Bag 8200, GCMC, Queensland, Australia

\section{PUBLISHED}

9 July 2021 Volume 21 Issue 3

\section{HISTORY}

RECEIVED: 7 September 2020

REVISED: 12 April 2021

ACCEPTED: 28 April 2021

\section{CITATION}

Tujague NA, Ryan KL. Ticking the box of 'cultural safety' is not enough: why trauma-informed practice is critical to Indigenous healing. Rural and Remote Health 2021; 21: 6411. https://doi.org/10.22605/RRH6411

\section{ETHICS APPROVAL}

This is a review article and not based on a specific research project.

This work is licensed under a Creative Commons Attribution 4.0 International Licence

\section{ABSTRACT:}

It is critical that those working with Aboriginal and Torres Strait Islander communities acknowledge and understand the impacts of trauma in order to engage in culturally safe practice. Recognising the role that historical and other traumas play in Indigenous people's communities and lives is a prerequisite for respectful and safe practice.

Culturally safe, trauma-informed practice training makes cultural safety more achievable. Organisations that are serious about working and partnering with Aboriginal and Torres Strait Islander peoples are becoming 'trauma informed'. Aboriginal and Torres Strait Islander peoples are drawing immense strength and hope from understanding trauma and its impact on their lives. Sharing this knowledge with Aboriginal and Torres Strait Islander populations also has the potential to create safe healing spaces 
and interrupt trauma being passed on through generations. Trauma-informed cultural safety can allow profound change for Keywords:

Australia, First Nations peoples, Aboriginal and Torres Strait Islander, cultural awareness, cultural lens, cultural safety, decolonising trauma studies, trauma-informed training, culturally safe trauma-informed practice.

\section{FULL ARTICLE:}

\section{Context}

Culturally safe, trauma-informed practice training is essential to achieve cultural safety and healing. For several years, The Seedling Group and other Indigenous organisations have been training government teams, not-for-profit organisations and Aboriginal and Torres Strait Islander communities to work in culturally safe and trauma-informed ways. We have found that understanding the impacts of trauma has the power to enable systems to repair and communities and individuals to heal.

This article examines the origins of cultural safety as a practice for working with Indigenous peoples, demonstrating its flaws and shortcomings. We argue that, without an understanding of the impacts of trauma, ticking the box of cultural safety training is not enough.

Colonisation has inflicted immense damage on the traditional diets, lore, land ownership and ways of living that kept First Nations peoples thriving for more than 50000 years ${ }^{\mathbf{1}}$. The violent acts of colonisation, including genocide ${ }^{2}$, have left a devastating legacy ${ }^{3}$. Historical trauma, collective trauma ${ }^{4}$ and cultural trauma $\mathbf{5}^{\mathbf{5}}$ have broken down the fabric of a once rich and healthy culture. Misguided policies and service-delivery practices are perpetuating systemic racism ${ }^{\mathbf{6}}$, and unless we incorporate an understanding of trauma into cultural safety training, we cannot become culturally safe in our practice.

Initiatives to create health and economic equity for Aboriginal and Torres Strait Islander peoples have lacked long-term planning and have proved costly ${ }^{\mathbf{7}}$. Governments and policy makers now concede that Aboriginal and Torres Strait Islander peoples must either lead, or be part of the design of, programs that are meant for them 8 and it is clear that government initiatives must be grounded in trauma-informed principles.

\section{Cultural safety: a short history}

The term cultural safety was coined by Māori nurse and scholar Irihapeti Ramsden in the 1990s. Ramsden worked hard to challenge the view that everyone should be cared for in the same way, 'regardless of who they were' ${ }^{\mathbf{9}}$, and eventually the Nursing Council of New Zealand endorsed cultural safety as a requirement for nursing and midwifery education.

Cultural safety was seen as a step beyond cultural awareness and cultural sensitivity. Cultural awareness is acknowledging that someone you are working with has a culture different to yours. Cultural sensitivity is taking steps to understand your own culture and life experiences, and how they impact others. Finally, cultural safety is said to be present when the recipient of your work individuals and the systems within which they practice.

considers you safe and not a threat to their culture being accepted. To be culturally safe is to understand one's own culture and the cultures of others without judgement. Only the recipients of care can say if that care is culturally safe ${ }^{\mathbf{1 0}}$.

Australian doctor Mary Belfrage learned the meaning of cultural safety in a remote Indigenous community in Alyawarr country north-west of Alice Springs. Belfrage found that 'people need to feel like themselves and believe that the health care is connected to their lives $\mathbf{1 1}^{\mathbf{1}}$ - a clear explanation that can be applied across all disciplines. Belfrage's cultural awareness emerged from learning about a new culture, and from a deep understanding of the trauma that permeated the community ${ }^{\mathbf{1 1}}$. We argue that genuine cultural safety must be grounded in a knowledge of trauma and its impacts on individuals, families and communities.

\section{Issues}

In Australia, despite three decades of cultural safety training, the gap between Indigenous and non-Indigenous health has widened in many areas $\mathbf{1 2}^{\mathbf{2}}$ and institutional racism continues ${ }^{\mathbf{1 3}}$.

Those who subscribe to the concept of cultural safety need to recognise and unpack racism that can be interpersonal, covert, overt, institutional or systemic ${ }^{6}$. It is rare for practitioners to reflect on the intergenerational privilege ${ }^{\mathbf{1 4}}$ and white privilege ${ }^{\mathbf{1 5}}$ that contribute to the equity gap. We argue that closing the gap between knowledge and practice also requires understanding the impacts of trauma and reflecting upon one's own culture and privilege. A deep knowledge of trauma, combined with critical selfreflection, makes it possible to change belief systems and behaviours.

Trauma-informed practice asks, 'What is that person's story?' rather than, 'What is wrong with that person?' Neurological research supports the view that unresolved trauma resides within the body as physiological memories, leading to distress, discomfort and disassociation when certain triggers are encountered ${ }^{\mathbf{1 6}}$. Traumainformed care reduces the risk of re-traumatisation by being sensitive to individuals' needs. Trauma-informed care involves trauma screening, building safe working relationships and managing patient disclosure and distress ${ }^{\mathbf{1 7}}$.

An understanding of the Indigenous model of health is necessary to prevent re-traumatisation. This model embraces connection to country, spirit, spirituality, ancestors, culture, community, family, kinship, the physical body, mind and emotions ${ }^{\mathbf{1 8}}$. Social and emotional wellbeing is tied to the broader social determinants of poverty, racism, unemployment and lack of safe housing. Trauma related to any of these domains affects the social and emotional wellbeing of Aboriginal and Torres Strait Islander peoples ${ }^{\mathbf{1 8}}$. 
Trauma-informed care and practice for Australian Indigenous peoples is not well researched or implemented ${ }^{\mathbf{1 7}}$ although we can learn much from important research from Canada ${ }^{3}$. A recent report highlights the need for trauma-informed care for Aboriginal and Torres Strait Islander peoples, and the need to understand the relationship between cultural competency training and traumainformed practice ${ }^{\mathbf{1 9}}$. Aboriginal psychologist Tracy Westerman links 'race-based' trauma to Indigenous suicide, suggesting that trauma has become a central organising principle in the psychological structures of some individuals and communities ${ }^{\mathbf{2 0}}$

While cultural safety training is important, unless we acknowledge the trauma experienced by the developing child, it is difficult to grasp the intergenerational impacts of disadvantage, chronic health outcomes and inequity ${ }^{4}$. The Adverse Childhood Events (ACEs) study found that those who suffered childhood trauma have an increased risk of chronic disease $\mathbf{2 1}^{\mathbf{2 1}}$ and re-traumatisation ${ }^{\mathbf{2 2}}$.

Individuals whose families have been subjected to wars, residential schooling, stolen generations, oppression and racism can experience intergenerational trauma ${ }^{\mathbf{4}}$. Trauma is passed on through generations by disruptions to attachment and the resulting coping strategies ${ }^{3}$. Atkinson mapped the transmission of trauma through six generations of one Aboriginal family ${ }^{23}$. The science of epigenetics now recognises the effect of trauma on gene expression, and it provides us with what is possibly the most detailed explanation to date of the transmission of trauma through the generations ${ }^{\mathbf{2 4}}$.

Survivors of intergenerational trauma adopt coping mechanisms including addiction, self-harm, suicidal ideation, chronic hypervigilance and hyperarousal ${ }^{\mathbf{2 5}}$. Complex trauma leads to overrepresentation in care facilities ${ }^{\mathbf{2 6}}$ and juvenile justice and prison systems ${ }^{\mathbf{2 7}}$, and it creates barriers to accessing services ${ }^{\mathbf{2 8}}$. The history of broken family attachment continues today with forced infant removals 29 .

Cultural safety training does not address the impacts of intergenerational and other complex traumas. Policy makers and practitioners accept research findings about trauma's impact on the body, but have so far failed to reform our systems, policies and laws, despite trauma being central to the stories of most individuals who battle mental health disorders and substance abuse $^{30}$.

\section{Lessons learned}

Trauma-informed practice training delivered through a cultural lens considers Aboriginal and Torres Strait Islander perspectives of health and their experiences of historical and cultural trauma, racism and discrimination. Acknowledging the damage from colonisation and ongoing government policies has given Aboriginal and Torres Strait Islander peoples a foundation to begin healing families and communities. Culturally safe, trauma-informed practice also takes into account Indigenous peoples' unique strengths and resilience and stories of survival.

Ward et al found that the unsolicited, informal support of peers, Elders and other community groups played a significant role in supporting those with chronic illnesses ${ }^{\mathbf{3 1}}$. They identified a need for more education and knowledge for support groups. Sharing knowledge about trauma has been embraced by these groups, which has led to early identification of trauma conditions, informed support, awareness and empowerment within communities.

The Seedling Group first delivered its training to government departments and non-government organisations. Then we began to get calls from women's shelters, schools and other grassroots organisations. We have found community to be the most inspiring and rewarding environment in which to deliver our training. Sharing knowledge can have vast ripple effects. One Aboriginal participant shared her knowledge with 22 people in her extended family. This knowledge sharing enabled her to understand her personal and work challenges, and to adopt life-changing coping strategies.

An understanding of trauma tells us it goes against common sense to incarcerate a 10-year-old child or suspend a student for their problematic behaviour. Culturally safe, trauma-informed practice creates a safe space that allows healing to happen. It means hearing the whole story of a person before making a judgement. It is at its most powerful when Indigenous individuals and organisations work towards interrupting their own intergenerational trauma.

The Seedling Group worked with one such organisation of Stolen Generation men. Their aim was to interrupt the handing down of trauma through their family lines. These men had been stripped of their culture, and told their families had discarded them, or were lost or dead. In a conversation in April 2019, a surviving Uncle revealed that these men were frequently told they were dumb and incapable of learning. Their healing started with sharing and understanding the trauma they had suffered. The benefits of such sharing are beyond profound; they are the very essence of healing our families and communities.

The Seedling Group's approach to interrupting intergenerational trauma is to deliver training to those working with First Nations peoples about culturally safe, trauma-informed practice and care through an Indigenous lens. Other Indigenous organisations working towards community recovery from trauma include the Family Wellbeing Program ${ }^{32}$, We al-li33, Yarning up on Trauma ${ }^{34}$, Red Dust Healing ${ }^{\mathbf{3 5}}$, the Djirruwang Program ${ }^{\mathbf{3 6}}$ and many others.

Aboriginal and Torres Strait Islander peoples are beginning to understand the trauma that affects their lives. Reeves suggests that trauma training for survivors can empower them in their healthcare interactions ${ }^{\mathbf{1 7}}$. When we carried out trauma training to professionals and community members in one Indigenous community, participants demanded that it be given to teachers at the local school, where children were being punished for things like sleeping during class with their heads on their desks. Staff seemed insensitive to the challenges being faced in the home and community. For community members, knowledge became a tool to demand changes to service delivery in their community.

\section{Conclusion}


Cultural safety training has failed Aboriginal and Torres Strait Islander Australians. Now is the time to become trauma-informed, and only that knowledge will allow profound change to the individuals who make up our systems, improving the potential to close the gap between Indigenous and non-Indigenous

Australians. We suggest the teaching of cultural safety has become a mere instrument of compliance. To be truly culturally safe is to understand how the history of trauma suffered by Aboriginal and Torres Strait Islander Australians has led to social, emotional and economic disadvantage. What we know about trauma and its effects on the body can greatly influence our journey to becoming culturally safe in our work with all First Nations peoples.

Understanding trauma can move us past racist assumptions and help us change our systems and policies. Most importantly, for First Nations peoples, understanding trauma helps us to explore the strengths of our holistic cultures and how we thrived before the injustices of colonisation.

\section{Acknowledgements}

We gratefully acknowledge the Aboriginal and Torres Strait Islander peoples who have contributed to this article by way of their stories, knowledge, learning and resilience despite experiencing deep trauma. We also acknowledge Kath Fisher and Elizabeth Rix for their critical review of this manuscript. We thank Dr Shawn Wilson and Dr Stuart Barlo for their academic and cultural guidance.

\section{REFERENCES:}

1 Dudgeon P, Wright M, Paradies Y, Garvey D, Walker I. Aboriginal social, cultural and historical contexts. In: P Dudgeon, H Milroy, R Walker (Eds). Working together: Aboriginal and Torres Strait Islander mental health and wellbeing principles and practice. Barton, ACT: Commonwealth of Australia, 2014; 3-25.

2 Dudgeon $\mathrm{P}$, Milroy $\mathrm{H}$, Walker R. Community life and development programs - pathways to healing. In: P Dudgeon, $\mathrm{H}$ Milroy, R Walker (Eds). Working together: Aboriginal and Torres Strait Islander mental health and wellbeing principles and practice. Barton, ACT: Commonwealth of Australia, 2014; 419-436.

3 O'Neill L, Fraser R, Kitchenham A, MacDonald V. Hidden burdens: a review of intergenerational, historical and complex trauma, implications for Indigenous families. Journal of Child Adolescent Trauma 2016; 11: 173-186. DOI link, PMid:32318148

4 Menzies K. Understanding the Australian Aboriginal experience of collective, historical and intergenerational trauma. International Social Work 2019; 1: 13.

5 Salzman MB (Ed.). Cultural trauma and recovery. A psychology of culture. International and Cultural Psychology series. Cham: Springer, 2018. DOI link

6 Bourke CJ, Marrie H, Marrie A. Transforming institutional racism at an Australian hospital. Australian Health Review 2019; 43(6): 611-618. DOI link, PMid:30458120

7 Staines Z, Moran M. Complexity and hybrid effects in the delivery and evaluation of youth programmes in a remote Indigenous community. Australian Journal of Public Administration 2020; 79: 3-25. DOI link

8 Munro A. Healing together: identifying the value of partnerships between rural Aboriginal communities, services and researchers to co-design, implement and evaluate programs to reduce drug and alcohol harms. PhD thesis. Sydney, NSW: University of New South Wales, 2018.

9 Ramsden I. Cultural safety and nursing education in Aotearoa and Te Waipounamu. PhD thesis. Wellington, New Zealand: Victoria University of Wellington, 2002.

10 Ramsden I. Towards cultural safety. In: D Wepa (Ed.). Cultural safety in Aotearoa New Zealand. Port Melbourne, Vic: Cambridge
University Press, 2015; 3-25.

11 Belfrage M. Why 'culturally safe' health care? The Medical Journal of Australia 2007; 186(10): 537-538. DOI link, PMid:17516905

12 Australian Medical Association. AMA 2018 report card on Indigenous health. 2018. Canberra, ACT: Australian Medical Association.

13 Queensland Mental Health Commission. Don't judge, and listen. Brisbane, Qld: Queensland Mental Health Commission, 2020.

14 Swartz T. Family capital and the invisible transfer of privilege: intergenerational support and social class in early adulthood. New Directions for Child and Adolescent Development 2008; 119: 11-24. DOI link, PMid:18330916

15 Filor AM (Ed.). White privilege and male privilege: a personal account of coming to see correspondences through work in women's studies. Council of Educational Associations, Research and Development Committee. Wellesley, MA: New York State United Teachers, 1988.

16 Van der Kolk B. The history of trauma in psychiatry. Psychiatric Clinics of North America 1994; 17(3): 583-600.

17 Reeves E. A synthesis of the literature of trauma-informed care. Issues in Mental Health Nursing 2015; 36(9): 698-709. DOI link, PMid:26440873

18 Gee G, Dudgeon P, Schultz C, Hart A, Kelly K. Aboriginal and Torres Strait Islander social and emotional wellbeing. In: $P$ Dudgeon, H Milroy, R Walker (Eds). Working together: Aboriginal and Torres Strait Islander mental health and wellbeing principles and practice. Barton, ACT: Commonwealth of Australia, 2014; 55-68.

19 The Lowitja Institute. Journeys to healing and strong wellbeing final report. Melbourne, Vic: The Lowitja Institute, 2018.

20 Westerman T. Suicide risk factors are being incorrectly stated as suicide causes. 2019. Available: web link (Accessed 7 September 2020).

21 Felitti V, Anda RF, Nordenberg D, Williamson DF, Spitz AM, Edwards $V$, et al. Relationship of childhood abuse and household 
dysfunction to many of the leading causes of death in adults.

American Journal of Preventative Medicine 1998; 14(4): 245-258.

DOI link

22 Coles J, Jones K. Universal precautions: perinatal touch and examination after childhood sexual abuse. Birth 2009; 36: 230-236. DOI link, PMid:19747270

23 Atkinson J. Trauma trails, recreating songlines: the transgenerational effects of trauma in Indigenous Australia. Geelong, Vic: Spinifex, 2002.

24 Zannas AS, Provencal N, Binder EB. Epigenetics of posttraumatic stress disorder: current evidence, challenges, and future directions. Biological Psychiatry 2015; 78(5): 327-335.

25 Bloom SL. Trauma theory. In: R Benjamin, J Haliburn, S King (Eds). Humanising mental health care in Australia. New York, NY: Routledge, 2019; 3-30. DOI link

26 McPherson L, Gatwiri K, Tucci J, Mitchell J, Macnamara N. A paradigm shift in responding to children who have experienced trauma: the Australian Treatment and Care for Kids program. Children and Youth Services Review 2018; 94: 525-534. DOI link

27 Gilligan J. Violence: our deadly epidemic and its causes. New York, NY: GP Putnam's Sons, 1996.

28 Haythornthwaite S, Hirvonen T. The relevance of trauma informed care to Aboriginal primary health care services. Darwin, NT: 13th National Rural Health Conference, 2015.

29 O'Donnell M, Taplin S, Marriott R, Lima F, Stanley F. Infant removals: the need to address the over-representation of Aboriginal infants and community concerns of another 'stolen generation'. Child Abuse \& Neglect 2019; 90: 88-98. DOI link, PMid:30769191
30 Delima J, Vimpani G. The neurobiological effects of childhood maltreatment. Family Matters 2011; 89: 42-52.

31 Ward NJ, Jowsey T, Jaora PJ, Aspin C, Yen E. With good intentions: complexity in unsolicited informal support for Aboriginal and Torres Strait Islander peoples. A qualitative study. BMC Public Health 2011; 11: 686. DOI link, PMid:21888670

32 Tsey K, Whiteside M, Haswell-Elkins M, Bainbridge R, CadetJames Y, Wilson A. Empowerment and Indigenous Australian health: a synthesis of findings from Family Wellbeing formative research. Health and Social Care in the Community 2010; 18(2): 169-179.

33 Atkinson J, Ober C. We Al-li 'fire and water': a process of healing. In: M Hazlehurst (Ed.). Popular justice and community regeneration: pathways of Indigenous reform. Westport, CT: Greenwood, 1995.

34 Coade S, Downey L, McClung L. Yarning up on trauma: healing ourselves, healing our children and families, healing our communities. Melbourne, Vic: Berry Street, 2008.

35 Powell T, Ross R, Kickett D, Donnelly J. Red dust healing: acknowledging the past, changing the future. In: P Dudgeon, $\mathrm{H}$ Milroy, R Walker (Eds). Working together: Aboriginal and Torres Strait Islander mental health and wellbeing principles and practice. Barton, ACT: Commonwealth of Australia, 2014; 459-474.

36 Brideson T, Havelka J, McMillan F, Kanowski L. The Dijurruwang Program: cultural affirmation for effective mental health. In: P. Dudgeon, H. Milroy, and R. Walker (Eds). Working together: Aboriginal and Torres Strait Islander mental health and wellbeing principles and practice. Barton, ACT: Commonwealth of Australia, 2014; 423-532.

This PDF has been produced for your convenience. Always refer to the live site https://www.rrh.org.au/journal/article/6411 for the Version of Record. 